\title{
Immunostimulation increases the resistance of mouse embryos to the teratogenic effect of diabetes mellitus
}

\author{
A . Torchinsky, V. Toder, S. Savion, J. Shepshelovich, H . O renstein, A . Fein \\ Department of Embryology and Teratology, Sackler School of Medicine, Tel Aviv University, Tel Aviv, Israel
}

Summary The present work was aimed to assess the possible effect of stimulation of the maternal immune system on the teratogenic potential of diabetes mellitus. ICR female mice were immunized with splenocytes of male rats 3 weeks before the beginning of mating and were injected with $240 \mathrm{mg} / \mathrm{kg}$ streptozocin (STZ) 10 days after immunization. Females with blood glucose levels over $27.8 \mathrm{mmol} / \mathrm{l}$ and $\mathrm{HbA}_{1 \mathrm{c}}$ levels over 6 standard deviations (SD) above the mean of intact animals were used for teratological studies. The rate of malformed fetuses, resorptions and fetal weights were evaluated for animals killed on day 19 of pregnancy using routine teratological methods. Also, phenotyping of spleen cells of these females was performed by fluorescein activated cell sorter analysis. Two main effects possibly due to immunostimulation of ICR females were observed: 1) immunostimulated females had significantly fewer litters with malformed fetuses than non-immunized females: only 4 litters out of $22(18 \%)$ compared to 10 out of $16(63 \%)$. Correspondingly, the incidence of malformed fetuses was also decreased: 2.1 compared to $8.9 \% ; 2$ ) a significant increase in the pregnancy rate in immunized diabetic ICR mice: $69 \%$ as compared to $44 \%$ in non-immunized diabetic females. Also, immunostimulation resulted in a visible increase in spleen cellularity and a certain increase in the number of cells with mature T-cell and macrophage surface markers. These results strongly suggest that immunostimulation increases the tolerance of ICR females to the teratogenic effect of STZ-induced diabetes. [Diabetologia (1997) 40: 635-640]

Keywords Diabetes mellitus, teratogenesis, inborn anomalies, immunostimulation, immune system.
Meticulous metabolic control of diabetes mellitus has significantly decreased the risk of gross structural malformations in newborns. Nevertheless, the incidence of malformed newborns in women with insulin-dependent diabetes mellitus (IDDM) $(6-10 \%)$ is still three to five times higher than that among nondiabetic women $[1,2]$.

Received: 23 December 1996 and in revised form: 4 March 1997

Corresponding author: Dr. A. Torchinsky, Department of Embryology and Teratology, Sackler School of Medicine, Tel Aviv University, Ramat Aviv, Tel Aviv 69978, Israel

A bbreviations: IDDM, Insulin-dependent diabetes mellitus; STZ, streptozotocin; PBS, phosphate buffered saline; FITC, fluorescein isothiacyanate.
Studies aimed at eliciting the etiology and the pathogenesis of these malformations suggested that the latter may be due to interaction between diabetes-associated teratogenic metabolites (e.g. glucose, ketone bodies, somatomedin inhibitors) and some internal factors, which may have a distorted influence on the embryonic development in diabetic patients [3]. We hypothesized that immune responses operating in the 'mother-fetus' axis may be one of these factors. These responses may include activation of various immunocompetent cells in the maternal circulation, antipaternal and antifetal antibodies with the accumulation of natural killer cells and macrophages in the pregnant uterus capable of releasing a variety of cytokines which, in turn, clearly influence patterns of fetal development [4].

Three facts are in support of such a hypothesis: 
1. Maternal immune responses were shown to be an important factor in determining patterns of embryonic development and, correspondingly, the pregnancy outcome [5]. Furthermore, the use of active immunization with paternal leucocytes or passive immunization with immunoglobulin for the prevention of recurrent human miscarriage or spontaneous embryonic loss in animal models is widely reported [4].

2. IDDM is accompanied by immune disorders [6] that were suggested to affect the mother's ability to mount an appropriate immune response toward her fetuses [7]. Supporting evidence has recently been provided by a study demonstrating that production of tumour necrosis factor-alpha is upregulated in the uterus of diabetic rats during the implantation phase [8]. This effect was found to be associated with developmental deficiencies in preimplantation embryos.

3. Our studies have demonstrated that stimulation of the maternal immune response enhances the embryo's tolerance to environmental chemical teratogens [9]. Such stimulated immunoreactivity of female mice enhanced the tolerance of embryos to two reference teratogens, dioxidine and cyclophosphamide [10]. Depression of the maternal immune response by excising the para-aortic lymph nodes draining the uterus significantly strengthened the effect of both teratogens [11]. Based on these findings we concluded that maternal immune responses may be one of the factors determining the embryo's susceptibility to teratogens.

In our opinion, the role of fetomaternal immune interactions in determining the teratogenic response to diabetes remains to be studied. This fact and the above findings gave us the impetus to study the possible effect of stimulation of the maternal immune system on the teratogenic potential of streptozotocin (STZ)-induced diabetes.

\section{Materials and methods}

A nimal model. We used 6-8 week old ICR mice obtained from the Tel Aviv University animal facility for this study. The animals were maintained on a $14 \mathrm{~h}$ light $/ 10 \mathrm{~h}$ dark cycle with food (Purina Lab Chow, Kofolk, Tel Aviv, Israel) and tap water ad libitum. To induce diabetes, ICR female mice were injected (i.p.) with $240 \mathrm{mg} / \mathrm{kg} \mathrm{STZ} \mathrm{(Sigma,} \mathrm{St.} \mathrm{Louis,} \mathrm{Mo.,} \mathrm{USA)} \mathrm{in} \mathrm{buf-}$ fer acetate, $\mathrm{pH}$ 4.2. This dose was shown to induce diabetes in approximately $75 \%$ of mice $48 \mathrm{~h}$ after injection [12].

To modulate maternal immune responses, ICR female mice underwent intrauterine immunization with rat splenocytes 3 weeks before the beginning of mating. Splenocytes from Long-Evans male rats were prepared and injected according to methods described elsewhere [10]. Briefly, spleens were aseptically removed and dispersed in RPMI-1640 medium (Biolab, Jerusalem, Israel) by pressing them through a stainless steel mesh. The cells were washed and resuspended to reach the required concentration. With the mouse under nembutal anaesthesia $(40 \mathrm{mg} / \mathrm{kg})$ the uterus was identified and injected with $0.04 \mathrm{ml}$ suspension of $25-30 \times 10^{6}$ splenocytes per horn.
The effectiveness of the intrauterine route for immunization with rat splenocytes in modifying the embryo's sensitivity to the teratogenic insult was shown in our previous studies with cyclophosphamide [13].

It is clear that to elicit any factor modifying the embryo's sensitivity to the teratogenic insult, experimental animals have to demonstrate a relatively high rate of malformed fetuses. Meanwhile, STZ-induced diabetes in rodents, unlike chemical reference teratogens, exerts a relatively weak teratogenic effect: only $5-10 \%$ of fetuses have major anomalies [14]. Therefore, only diabetic ICR females with blood glucose levels over $27.8 \mathrm{mmol} / \mathrm{l}$ and $\mathrm{HbA}_{1 \mathrm{c}}$ levels over 6 standard deviations (SD) above the mean of intact ICR females were used in the present work.

Such a choice was based on previous results showing that the incidence of litters with malformed fetuses in females with these glucose and $\mathrm{HbA}_{1 \mathrm{c}}$ levels was approximately $60 \%$ [15]. It was also shown that the mathematical expectation of the share of pregnant diabetic females with glucose level over $27.8 \mathrm{mmol} / \mathrm{l}$ and $\mathrm{HbA}_{1 \mathrm{c}}$ level over $6 \mathrm{SD}$ above the mean in a group of ICR mice treated with $240 \mathrm{mg} / \mathrm{kg} \mathrm{STZ}$ is, approximately 0.05 and about $20-30 \%$ of STZ-treated ICR mice die within 1 week after the STZ injection.

Therefore, two groups of STZ-treated animals were used in the present study: 1) 400 females underwent immunization with rat splenocytes and were injected with STZ 10 days after immunization; 2) 400 females were injected with $0.04 \mathrm{ml}$ saline in each horn of the uterus 3 weeks before the beginning of mating and also treated with STZ as mentioned above. Also, $25 \mathrm{fe}-$ males immunized with rat splenocytes according to the schedule mentioned above were used as a concurrent control to estimate the effect of immunization itself on the reproductive performance of ICR female mice.

The evaluation of diabetic status. The glucose level in the maternal blood of STZ-treated and control animals was measured on day 19 of pregnancy with a commercially available glucometer (Accutrend; Boehringer Mannheim GmbH, Mannheim, Germany) according to the manufacturer's instructions. $\mathrm{HbA}_{1 \mathrm{c}}$ level was measured by the Abbott IMx Glycated Hemoglobin assay (Abbott Laboratory, Abbott Park, Ill., USA) which is an ion capture assay using boronate affinity binding to measure the percentage of glycated haemoglobin $(\% \mathrm{Hb})$, and is also standardized to report the percentage of haemoglobin $A_{1 c}[16]$.

The same methods were used to examine glucose and $\mathrm{HbA}_{1 \mathrm{c}}$ levels in 20 age-matched intact females on the day of STZ-treatment. Results obtained were used to detect the onset and the severity of diabetes in STZ-treated mice. Since in intact agematched females glucose level (mean \pm SD) was $6.54 \pm$ $0.96 \mathrm{mmol} / \mathrm{l}$, STZ-treated females with glucose level over $9.42 \mathrm{mmol} / \mathrm{l}$ (mean $\pm 3 \mathrm{SD}$ ) were considered to be diabetic. Correspondingly, the $\mathrm{HbA}_{1 \mathrm{c}}$ level of these females, $4.48 \pm 0.44 \%$ (mean $\pm \mathrm{SD}$ ), was used to separate diabetic females with $\mathrm{HbA}_{1 \mathrm{c}}$ levels over $6 \mathrm{SD}$ above the mean (i.e. $>7.12 \%$ ).

Teratology. STZ-treated and control females were caged with males 10 days after STZ injection. Females were mated by caging with males overnight 5 days per week for 5 weeks. The presence of a vaginal plug was designated as day 1 of pregnancy. The females were killed on day 19 of pregnancy, the uteri were removed and the numbers of implantation sites, resorptions and live fetuses were recorded [17]. Then, the resorption rate (proportion of dead embryos and fetuses to implantation sites) and the pregnancy rate (proportion of pregnant to mated females) were calculated.

All live fetuses were weighed and examined for gross structural malformations. Soft tissue anomalies were also assessed 
Table 1. Diabetes-induced teratogenic effect in diabetic immunized and non-immunized ICR mice

\begin{tabular}{llll}
\hline Incidence & Animals & & \\
\cline { 2 - 4 } & Control & $\begin{array}{l}\text { Diabetic } \\
\text { (non-immunized) }\end{array}$ & $\begin{array}{l}\text { Diabetic } \\
\text { (immunized) }\end{array}$ \\
\hline No. mated females & & 36 & 32 \\
No pregnant females & 21 & 16 & 22 \\
Pregnancy rate (\%) & 18 & $44.4^{\mathrm{b}}$ & $68.8^{\mathrm{a}}$ \\
Implantation sites & $85.7^{\mathrm{a}}$ & $11.2 \pm 0.6$ & $10.9 \pm 0.8$ \\
Percent of postimplantation & $11.8 \pm 0.7$ & 31.3 & 21.7 \\
loss (arcsine) & 12.3 & $(34.9 \pm 5.1)^{\mathrm{b}}$ & $(29.3 \pm 4.6)^{\mathrm{ab}}$ \\
Fetal weight (g) & $(22.6 \pm 2.5)^{\mathrm{a}}$ & $1.03 \pm 0.07^{\mathrm{b}}$ & $1.12 \pm 0.06^{\mathrm{b}}$ \\
No. malformed fetuses (\%) & $1.42 \pm 0.08^{\mathrm{a}}$ & $11(8.9)$ & $4(2.1)$ \\
(arcsine) & 0 & $(20.1 \pm 2.3)^{\mathrm{b}}$ & $(14.3 \pm 3.6)^{\mathrm{ab}}$ \\
No. litters with malformed fetuses (\%) & $(8.6 \pm 0.2)^{\mathrm{a}}$ & $10(63)^{\mathrm{b}}$ & $4(18)^{\mathrm{a}}$ \\
\hline
\end{tabular}

Values are mean \pm SEM unless stated otherwise

Values not sharing common superscripts are significantly different $(p<0.05)$

by using Wilson's method [17] consisting of cutting a series of transverse sections. Since in our previous studies we have not observed significant disturbances in the ossification process in fetuses of STZ-induced diabetic ICR mice [15] fetuses were not examined for skeletal malformation.

Females were weighed at the beginning of the experiment and on the day of mating.

E valuation of maternal immune status. In order to test whether intrauterine immunostimulation influences various maternal immune parameters in diabetic mice, the number of splenocytes was counted and phenotyping of spleen cells was performed in diabetic and control (immunized) animals as well as in intact pregnant females (six samples were tested in each group). Spleens were cut into small pieces and teased into single cell suspensions. After elimination of erythrocytes by ammonium chloride buffer, the viable cells/spleen were counted using trypan blue staining to evaluate spleen cellularity.

A ntibodies. The following antibodies were used throughout the study: anti-CD5 (53-7-313), anti-CD4 (GK 1.5), anti-CD8 (53-6-72) and anti-Mac-1 (M1/70.15.11.45.HL). All antibodies were used as rat hybridoma cell line supernatants and were kindly provided by Professor I. Witz (Tel Aviv University, Israel). Fluorescein-isothiocyanate (FITC)-conjugated mouse anti-rat IgG (Fab fragment) was purchased from the Jackson Immunoresearch Laboratories (West Grove, Pa., USA).

E valuation of cell surface antigen expression. The spleen cells were washed once with phosphate buffered saline (PBS) without $\mathrm{Ca}^{++}$and $\mathrm{Mg}^{++}$, containing $0.1 \%$ bovine serum albumin and $0.01 \%$ sodium azide and samples of $0.5-1 \times 10^{6}$ cells were incubated with the monoclonal antibodies mentioned above $\left(30 \min , 4^{\circ} \mathrm{C}\right)$.

After one wash in PBS supplemented as mentioned above, the cells were reincubated with the FITC-conjugated secondary antibody $\left(30 \mathrm{~min}, 4^{\circ} \mathrm{C}\right.$, in the dark). After one wash in supplemented PBS and fixation in $0.5 \%$ paraformaldehyde, $1 \times 10^{4}$ cells/spleen were analysed by a fluorescence activated cell sorter (FACSort, Becton Dickinson FACS Systems, Mountain View, Calif., USA) and the level of cell surface antigens (fluorescence intensity) was measured. Dead cells were routinely excluded from analysis on the basis of forward versus side scatter and all data were expressed in logarithmic scale. Data were represented as the ratio between the percentage of spleen cells expressing a given marker in pregnant diabetic immunized and non-immunized mice compared to intact females [18].

\section{Statistical analysis}

Statistical analysis of the teratological data was performed on a litter basis. The proportion of malformed fetuses and resorptions per litter were transformed to arcsine values by Freeman-Tukey's binomial method as described elsewhere [11]. Then, statistical comparisons of these indices were made by Student's t-test. Fisher's exact test was used for the comparison of the number of pregnant females and affected litters. Also, Student's t-test was used to analyse spleen cellularity and results of phenotyping of spleen cells. The two-tailed level of significance of differences was 0.05 .

\section{Results}

The mean body weight of control and STZ-treated females was identical at the start of the study: $31.00 \pm 0.87$ and $32.00 \pm 0.76 \mathrm{~g}$, respectively (mean \pm SE). However, the weight of diabetic mated females did not change during the study period $(30.52 \pm 1.08 \mathrm{~g}$ in immunized and $30.21 \pm 0.91 \mathrm{~g}$ in non-immunized mated females) whereas the weight of control females increased $(35.10 \pm 0.81 \mathrm{~g})$.

Out of 400 non-immunized females treated with STZ, 36 mated diabetic females had a blood glucose over $27.8 \mathrm{mmol} / \mathrm{l}$ and $\mathrm{HbA}_{1 \mathrm{c}}$ level over 6SD above the mean. In the group of immunized animals, 32 mated diabetic females had such levels of glucose and $\mathrm{HbA}_{1 \mathrm{c}}$. Results characterizing the reproductive performance and the teratogenic response of these animals are summarized in Table 1.

Maternal diabetes in ICR mice was accompanied by the occurrence of fetuses with such structural anomalies as encephalocoel, anophthalmia, open eyelids, agnathia and micrognathia and a number of other structural malformations [15]. The incidence of such malformed fetuses in the group of non-immunized diabetic females was relatively low: only $8.9 \%$ of fetuses obtained had structural malformations. However, since only single malformed fetuses were observed in litters, the incidence of litters with 


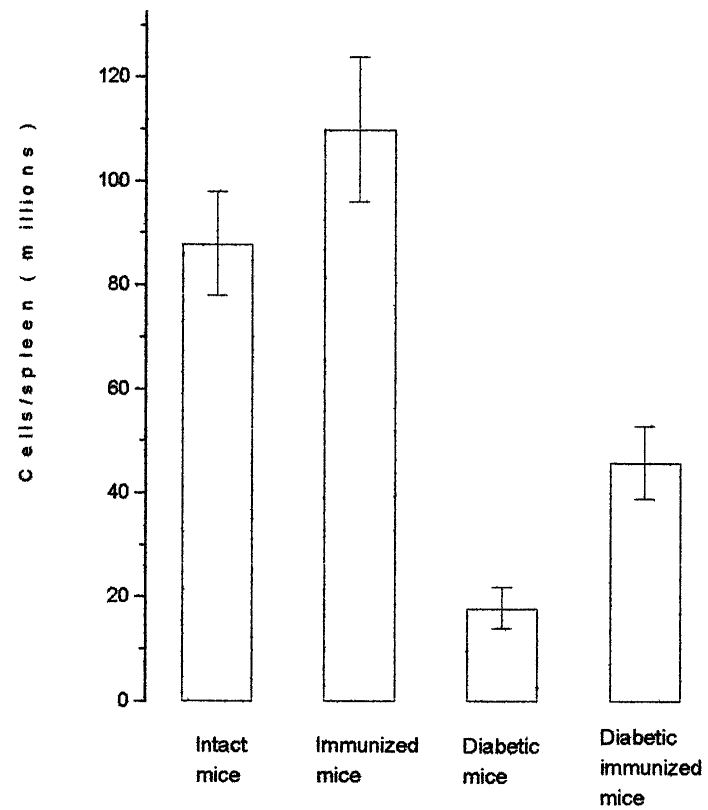

Fig. 1. Spleen cellularity in diabetic mice. Immunization did not significantly influence the number of spleen cells in non-diabetic mice. Diabetes significantly decreased spleen cellularity and immunization partly prevented such a decrease

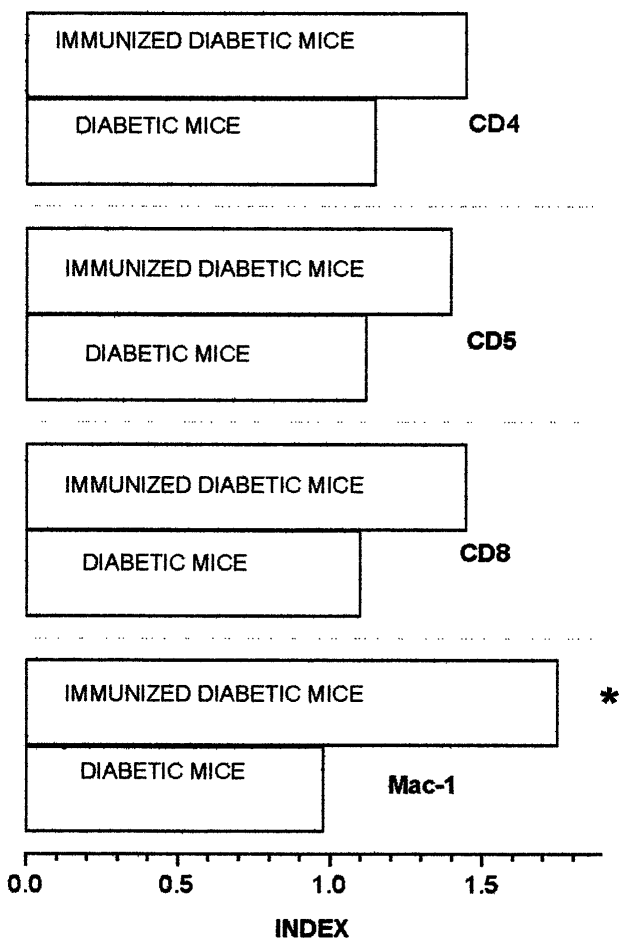

Fig. 2. Cell surface markers expressed by spleen cells collected from diabetic immunized and non-immunized mice. The index represents the ratio between the percentage of spleen cells expressing a given marker in experimental groups (pregnant diabetic immunized and non-immunized mice) vs non-diabetic intact mice. * Mac-1 antigen expression was observed to be significantly greater $(p<0.05)$ in immunized diabetic than in non-immunized diabetic mice malformed fetuses reached $63 \%$. Also, a dramatic decrease in the pregnancy rate was observed in these animals: 44.4 vs $85.7 \%$ in the group of non-diabetic controls.

Finally, an increased resorption rate (31.3 vs $12.3 \%)$ and a decreased fetal weight $(1.03 \pm 0.07$ vs $1.42 \pm 0.08 \mathrm{~g}$ in controls) were recorded in diabetic animals.

Two main effects that may be attributed to immunostimulation of ICR females are worth mentioning: 1) immunostimulated females had significantly fewer litters with malformed fetuses than non-immunized females: only 4 litters out of $22(18 \%)$ vs 10 out of 16 $(63 \%)$. Correspondingly, the incidence of malformed fetuses in these females was also decreased (2.1 vs $8.9 \%$ ) but this difference did not reach statistical significance; 2) a significant increase in the pregnancy rate in immunized diabetic ICR mice: 69 compared to $44 \%$ in non-immunized diabetic females.

The resorption rate in immunized females was lower than that in non-immunized females $(21.7$ vs $31.3 \%$ ) but this difference was found to be statistically insignificant.

Studies of maternal immune parameters revealed that STZ-induced diabetes in ICR mice was accompanied by a significant decrease in spleen cellularity while immunostimulation resulted in a visible increase in the number of cells/spleen in diabetic females (Fig. 1). In parallel, a clear increase in the number of Mac-1- positive cells was observed in immunized diabetic females while the number of CD4 and CD8-positive cells tended also to be elevated (Fig. 2). The level of cell surface antigen expression by spleen cells in immunized non-diabetic and intact mice was similar (data not shown).

\section{Discussion}

Gross structural anomalies were used in this study as the end point for detection of the diabetes-induced teratogenic effect. The incidence of fetuses with such anomalies in STZ-induced diabetic ICR mice, like in other rodent models was found to be low: approximately $9 \%$ of fetuses (11 of 123 ) had major malformations. Fortunately, it was observed that in ICR mice the embryo's response to diabetes varied significantly between litters but not within a litter: only single malformed fetuses were observed in litters of diabetic mice. Therefore, the decrease in the proportion of immunized females with malformed fetuses (from 63 to $18 \%$ ) is a clear indication that immunostimulation increased the tolerance of ICR females to the teratogenic effect of STZ-induced diabetes.

There are two possible explanations for the phenomenon. The first is that a decreased teratogenic effect of STZ-induced diabetes on immunostimulated females might be due to a weaker diabetes in these 
animals. Indeed, diabetes development in genetically diabetes-prone mice and rats as well as in STZ-induced diabetic animals was found to be prevented by immunostimulation with specific and non-specific triggers [6]. A significantly decreased lethality in STZ-induced diabetic ICR female mice which were immunized with rat splenocytes as compared to that in non-immunized females was also observed in the present study (approximately 12 and $24 \%$, respectively).

It is unlikely, however, that this factor could play a significant role in this study since all tested females had severe diabetes (blood glucose over $27.8 \mathrm{mmol} / \mathrm{l}$ and $\mathrm{HbA}_{1 \mathrm{c}}$ level over $6 \mathrm{SD}$ above the mean) and diabetes-induced teratogenic effect was shown as being independent of the degree of glycaemic exposure in the given range [15].

The second explanation stems from our data showing that intrauterine immunostimulation has the potential to influence the systemic immune response of females: it resulted in a clear increase in spleen cellularity as well as in the number of Mac-1 positive cells and in some elevation in the number of spleen-derived mature $\mathrm{T}$ cells. Such results provide a basis for suggesting that the immune status of immunized and non-immunized diabetic ICR females may be different and, hence, to imply immune interactions occurring in the 'mother-fetus' axis as a factor influencing the susceptibility of the embryo to diabetes-generated teratogenic metabolites. If so, the question arises whether pathways exist which could contribute to such an influence.

Since IDDM-induced major malformations are supposed to represent a threshold phenomenon as described by Fraser [19], its multifactorial/threshold model may be used to outline one of the possible pathways of interacting immune responses and teratogenic metabolites at the organism level.

According to Fraser's multifactorial/threshold model, patterns of genetically determined intermediate developmental phenomena that may be altered by a teratogen are continuously distributed in an embryonic population. These patterns determine the position of the development threshold beyond which an embryo cannot develop normally. In other words, whether or not an embryo will have 'spontaneous' anomalies is determined by whether this embryo is one side or the other of a developmental threshold. A teratogen perturbs these developmental phenomena putting more embryos in the treated than the untreated population beyond the development threshold. Both genetic and environmental factors may influence both the distribution of embryos relative to the threshold and the threshold. Hence, according to this model, the embryo's sensitivity to the teratogenic insult may be determined by factors influencing its developmental patterns long before the teratogenic insult acting usually at 'the critical period' of organogenesis.
Immune responses operating in the 'mother-fetus' axis are one of the important factors determining the outcome of embryo development: practically all intermediate developmental phenomena were shown to be under the control of cytokines produced by immunocompetent and uterine cells [20,21]. In terms of the multifactorial/threshold model these findings imply that immune responses operating during the preimplantation and/or early implantation periods are involved in determining the position of an embryo relative to the developmental threshold, and therefore determine its sensitivity to a teratogen acting at the period critical for the induction of malformations.

The diabetic environment was shown to retard the growth and development of preimplantation embryos $[12,22-24]$ and the decreased pregnancy rate in ICR diabetic mice observed in our study concurs with the above observations. The above mentioned studies $[6,8]$ suggest that these effects may at least in part, be mediated by immunological mechanisms. It is conceivable, therefore, that in embryos developing in a diabetes-distorted immune microenvironment, spatial and temporal parameters of developmental processes may be significantly modified at the moment of the teratogenic insult that was shown to disrupt embryonic development in the postimplantation period [25]. If so, the normalization of fetomaternal immune interactions by immunostimulation may be accompanied by an increased tolerance of embryos to diabetes-generated teratogenic metabolites.

The question of how immune substrates and teratogenic metabolites interact at the cellular and subcellular levels is not clear at present. Therefore we can only mention that in our previous studies a decreased incidence of fetuses with cyclophosphamideinduced major malformations in immunostimulated mice correlated with a decreased expression of cyclophosphamide-induced apoptosis in the target organs of embryos [26, 27] and that neural tube defects induced by diabetic pregnancy have recently been shown to be associated with induced apoptosis [28]. In turn, convincing evidence shows the involvement of such cytokines and growth factors as tumour necrosis factor-alpha, transforming growth factor- $\beta$, interleukin (IL)-3 and 6, insulin-like growth factor I and II in the pathways of apoptosis both non-associated and associated with the function of such genes as, for example, $\mathrm{p} 53$, bcl-2 or retinoblastoma $(\mathrm{Rb})$ gene $[29,30]$.

It appears these findings suggest some ways to research the mechanisms of immunomodulation of the teratogenic response to diabetes. A decreased teratogenic effect in STZ-induced diabetic mice undergoing non-specific immunostimulation observed in the present work seems a strong argument that studies on this topic should be performed. 
A cknowledgements. This study was supported by theGutwirth Scientific Foundation (USA); by the Israel Ministry of Health; by the Israel Ministry of Science and Technology. Special acknowledgment to Dr. Y. Shaham from Zer Laboratories in Tel Aviv for assistance and co-operation in measuring $\mathrm{HbA}_{1 \mathrm{c}}$.

\section{References}

1. Greene MF, Hare JW, Cloherty JP, Benacerraf BR, Soeldner JS (1989) First-trimester haemoglobin $A_{1}$ and risk for major malformation and spontaneous abortion in diabetic pregnancy. Teratology 39: 225-231

2. Reece EA, Homko CJ, Wu YK(1996) Multifactorial basis of the syndrome of diabetic embryopathy. Teratology 54: 171-183

3. Sadler TW, Hunter III ES, Wynn RE, Phillips LS (1989) Evidence for multifactorial origin of diabetes-induced embryopathies. Diabetes 38: 70-74

4. Toder V, Carp H, Strassburger D (1994) Maternal immune recognition of pregnancy. J Israel Med Sci 30: 787-792

5. Hunt JS (1992) Immunobiology of pregnancy. Curr Opin Immunol 4: 591-596

6. Rabinovitch A (1995) Perspectives in diabetes. Immunoregulatory and cytokine imbalances in the pathogenesis of IDDM. Therapeutic intervention by immunostimulation? Diabetes 43: 613-621

7. Hoet JJ, Reusenc-Billen B, Catalano M (1992) Immunological aspects of diabetic pregnancies. In: Coulam CB, Faulk WP, McIntyre WW (eds) Immunological obstetrics. Norton, New York, London, pp 518-528

8. Pampfer S, Yanderheyden I, Wuu Y-D, Baufays L, Maillet O, De Hertogh R (1995) Possible role of THF- in early embryopathy associated with maternal diabetes in the rat. 44: 531-536

9. Toder V, Torchinsky A (1996) Immunoteratology: where we are and where to go. Am J Rep Immunol 35: 114-117

10. Torchinsky A, Fein A, Carp HJA, Toder V (1994) MHCassociated immunopotentiation affects the embryo response to teratogens. Clin Exp Immunol 98: 513-519

11. Torchinsky A, Fein A, Toder V (1995) Immunoteratology: I. MHC involvement in the embryo response to teratogens in mice. Am J Reprod Immunol 34: 288-298

12. Beebe LFS, Kaye PL (1990) Preimplantation development in the streptozotocin-induced diabetic mouse. Reprod Fertil Dev 4: 407-412

13. Torchinsky A, Fein A, Toder V (1995) Modulation of embryo sensitivity to teratogen by nonspecific intrauterine immunopotentiation. Toxicol Methods 5: 131-141

14. Zusman I, Ornoy A (1990) Embryonic resistance to chemical and physical factors: manifestation, mechanisms, role in reproduction and adaptation to ecology. Biol Rev 65: 1-18
15. Torchinsky A, Toder V, Carp H, Orenstein H, Fein A (1997) In vivo evidence for the existence of a threshold for hyperglycemia-induced major fetal malformations: relevance to the etiology of diabetic teratogenesis. Early Pregnancy: biology and medicine. 2: 1-7

16. Wilson DH, Bogacz JP, Forsythe CM, Turk PJ, Lane TL, Gates RC, Brandt DR (1993) Fully automated assay of glycohaemoglobin with the IMx analyzer: novel approaches for separation and detection. Clin Chem 39: 2090-2097

17. Wilson JG (1965) Methods for administering agents and detecting malformations in experimental animals. In: Wilson JG, Warkany J (eds) Teratology: priniciples and techniques. University of Chicago Press, Chicago, pp 267-277

18. Savion S, Toder V (1995) Pregnancy-associated effect on mouse thymocytes in vitro. Cellular Immunol 162: 282-287

19. Fraser FC (1977) The multifactorial/threshold conceptuses and misuses. Teratology 14: 267-280

20. Hunt JS (1994) Immunologically relevant cells in the uterus. Biol Reprod 50: 461-466

21. Schwartzman RA, Gidlowski JA (1993) Apoptosis: the biochemistry and molecular biology of programmed cell death. Endocrine Reviews 14: 133-151

22. Vercheval M, De Hertogh R, Pampfer S et al. (1990) Experimental diabetes impairs rat embryo development during the preimplantation period. Diabetologia 33: 187-191

23. Beebe LFS, Kaye PL (1991) Maternal diabetes and retarded preimplantation development in mice. Diabetes 40: 457-461

24. Pamper S, Wuu YD, Vanderheyden I, De Hertogh R (1994) In vitro study of the carry-over effect associated with early diabetic embryopathy. Diabetologia 37: 855-862

25. Kalter H (1996) Reproductive toxicology in animals with induced and spontaneous diabetes. Reprod Toxicol 10: $417-438$

26. Torchinsky A, Savion S, Gorivodsky M et al. (1995) Cyclophosphamide-induced teratogenesis in ICR mice: the role of apoptosis. Teratogen Carcinog Mutagen 15: 179-190

27. Toder V, Savion S, Gorivodsky M et al. (1996) Teratogeninduced apoptosis may be affected by immunopotentiation. J Rep Immunol 30: 173-185

28. Hill AL, Cai J, Phelan SA, Loeken MR (1996) Identification of a cell cycle-regulated gene whose abnormal expression in embryos of diabetic mice is associated with neural tube defects. Diabetes 45 [Suppl 2]:57 (Abstract)

29. Bursh W, Oberhammer F, Shulte-Hermann R (1992) Cell death by apoptosis and its protective role against disease. TIPS 13: 245-251

30. Harrington EA, Fanidi A, Evan GI (1994) Oncogenes and cell death. Curr Opin Genet Dev 4: 120-129 